\title{
The Pollution Game: A Classroom Exercise Demonstrating the Relative Effectiveness of Emissions Taxes and Tradable Permits
}

\author{
Jay R. Corrigan* \\ Associate Professor of Economics \\ Kenyon College \\ Gambier, OH 43022 \\ E-mail: corriganj@kenyon.edu \\ Tel: 740-427-5281 \\ Fax: 740-427-5276
}

\begin{abstract}
This classroom game illustrates the strengths and weaknesses of various regulatory frameworks aimed at internalizing negative externalities from pollution. Specifically, the game divides students into three groups - a government regulatory agency and two polluting firms - and allows them to work through a system of uniform command-and-control regulation, a tradable emissions permit framework, and an emissions tax. Students observe how flexible, marketoriented regulatory frameworks can outperform inflexible command-and-control. More importantly given the ongoing debate about how best to regulate carbon dioxide emissions, students can also observe how the introduction of abatement-cost uncertainty can cause one marketoriented solution to outperform another.
\end{abstract}

Keywords: classroom experiments, emissions taxes, pollution, tradable emissions permits. JEL: A20, Q52, Q53, Q54, Q58.

* Special thanks to the organizers of and participants in the 2008 Allied Social Science Association Annual Meeting where this paper was first presented. I also thank three anonymous reviewers for their helpful comments and suggestions. 
Students in introductory and environmental economics courses learn that government regulators can employ policies such as uniform regulation, emissions taxes, or tradable emissions permits in response to the negative externalities from pollution. And though students learn that flexible, market-oriented policy options have the potential to produce more efficient outcomes, textbooks generally include little discussion of the relative strengths of various market-oriented frameworks.

This classroom game illustrates the efficiency gains from various government policies aimed at internalizing negative externalities, as well as problems that arise due to heterogeneous abatement costs, asymmetric information, and strategic behavior on the part of the regulated firms. While other games demonstrate different policies regulators can use to internalize negative externalities (e.g., Bergstrom and Miller 2000, Hazlett and Bakkensen 2005), none specifically highlight the distinct regulatory challenges these policies present.

In the absence of uncertainty about abatement costs, tradable permits and emissions taxes should be equally effective at bringing about the optimal level of pollution abatement. And unlike uniform command-and-control regulation, this result holds even if firms have heterogeneous abatement costs. A point that is more difficult to convey in undergraduate courses, but that is at least as important given the current debate over how governments should regulate carbon dioxide $\left(\mathrm{CO}_{2}\right)$ emissions, is how well we can expect tradable permit and emissions tax schemes to perform relative to one another if abatement costs are uncertain. This uncertainty could come from several sources. For example, suppose polluters have perfect information regarding their abatement costs, but have a strategic incentive to either over- or understate these true costs. In this case, the regulator will receive an imperfect signal of true abatement costs. 
If regulators overestimate the true marginal cost of abatement under an emissions tax framework, they will set the tax rate undesirably high. And if, as McKibbin and Wilcoxen (2002) argue, the marginal benefit of $\mathrm{CO}_{2}$ abatement in a given year is flat while the marginal cost increases rapidly, this higher tax rate leads to a modest level of overabatement and a modest deadweight loss. On the other hand, if regulators overestimate the true marginal cost of abatement under a tradable permit framework, they will issue an undesirably large number of permits. Under the same marginal benefit and marginal cost assumptions, this leads to a substantial level of underabatement and a deadweight loss much larger than that under a tax.'

\section{PROCEDURES}

The game takes about 50 minutes. It will work in classes with as few as three students or as many as 100 , but the ideal class size is probably between 15 and 30 students. ${ }^{2}$ The game, while designed primarily for undergraduate environmental economics courses, can be used in any public policy, environmental studies, or economics course that covers environmental regulation. The game is intended for students who have, at minimum, been introduced to the concepts of marginal analysis and externality. Students do not necessarily need to have been exposed to formal models of emissions taxes and tradable permits, but if they have not, the instructor will need to briefly explain the optimal strategies under each regime (i.e., the per-ton tax rate should equal the marginal benefit from abatement at the optimal level of pollution, and the number of permits issued should equal the optimal level of pollution).

The instructor begins by dividing the class into three groups of roughly equal size - the government regulatory agency, Ace Energy, and Deuce Petrochemical-giving each student in 
each group the appropriate instruction sheet. Condensed versions of these instructions are included in the Appendix. Note that Deuce's abatement costs are twice Ace's costs.

In the game's first phase the focus is on the government regulatory agency. The regulator's goal is to bring about the socially optimal level of abatement while at the same time minimizing cost to industry. The regulator's handout provides information about the social benefit associated with abatement (and, by extension, the social damage caused by pollution). The firms' abatement costs, on the other hand, are private information available only to a given firm. The regulator can ask each firm questions about its abatement cost structure (e.g., "What's your total cost of reducing pollution by 10 tons?" or "What's the additional cost of the 10th ton of abatement?"), though firms are free to respond strategically. While this questions-and-answers stage can be as structured or as informal as an instructor chooses, one effective strategy is to instruct the regulator to come up with a fixed number of questions (e.g., four) that it will write on the board with the understanding that both firms will then answer these and only these questions. Experience suggests that both firms will likely overstate their abatement costs. Astute regulators will recognize this and do their best compensate.

Once the regulator has arrived at its best estimate of the optimal level of abatement, it simultaneously constructs three distinct pollution control schemes: (1) a uniform command-andcontrol framework requiring both firms to reduce emissions by the same amount, (2) a cap-andtrade framework where the regulator makes available a fixed number of pollution permits, and (3) an emissions tax framework where each firm has to pay a fixed dollar amount for each ton of pollution it chooses to generate.

In the game's second phase attention turns to the polluting firms. The firms begin by choosing their level of abatement in response to the regulator's command-and-control regulation. 
This is straightforward since both firms are instructed to reduce emissions by the same amount. Each firm then calculates (but does not reveal) the total cost of compliance with this regulatory structure, and the regulator announces the total benefit society derives from abatement. Finally, the instructor announces the extent of the deadweight loss under command-and-control regulation. Note that it is important that the instructor not announce at this stage whether the deadweight loss is the result of too much pollution, too much abatement, or simply a misallocation of abatement across firms. This would take away some of the suspense from later regulatory rounds and might give a firm information about its rival's abatement cost structure.

In the second regulatory round, the regulator allocates tradable emissions permits to firms. At the instructor's discretion, these permits can either be auctioned off or given away to firms for free. In the former case, an ascending-price English auction works well and should be familiar to students. The instructor starts by naming a low selling price (e.g., $\$ 5$ per permit), then raises the price incrementally until one firm drops out of the auction. In the interest of time, the instructor may want to start by auctioning off a bundle of five permits, then auction subsequent permits individually. If permits are to be given away, the instructor should also allow firms to trade permits informally. Here, each firm might select one student to bargain over the price and quantity of permits bought from or sold to the competing firm. These deliberations are made openly so that everyone in class can observe. The instructor could encourage these two students to begin their bargaining with questions like "What's the lowest price you'd be willing to sell one permit for?" or "What's the highest price you'd be willing to pay for five permits?" Both bargainers are, of course, free to respond to these questions strategically, though a few minutes of negotiating generally allows students to reach some kind of agreement. The instructor may wish to limit these negotiations to five minutes to keep the game moving. 
Once permits are allocated, the regulator again announces the total benefit from abatement, and firms calculate the total cost of compliance net any proceeds from permit sales or purchases. The instructor then announces the deadweight loss for this second regulatory round. Deadweight loss under permits will generally be less than that under command-andcontrol regulation unless permits were allocated very poorly at the end of the permit negotiations or the regulator chooses to allow a less-optimal quantity of pollution than in the command-andcontrol round. To help students understand why this market-oriented framework outperforms command-and-control, the instructor can ask the firms to announce their total abatement costs under both the command-and-control and cap-and-trade regulatory frameworks. Assuming the regulator settled on the same level of pollution under both schemes, the total level of abatement (and therefore total damage from pollution) will be the same in both rounds, but introducing a market for permits allows industry to achieve a given level of abatement at lower cost.

In the third and final regulatory round, firms respond to the emissions tax set by the regulator in the game's first phase by choosing a level of abatement that minimizes compliance costs, in this case defined as abatement costs plus total emissions taxes paid. This should be a straightforward application of the equimarginal principle (i.e., firms abate so long as the cost of one more ton of abatement is less than or equal to the cost of paying the emissions tax). Experience suggests, however, that students may need a gentle reminder. Once both firms have determined their optimal abatement levels, they can announce what these levels are along with their total compliance costs. The regulator again calculates and announces the total benefit from abatement, and the instructor announces the deadweight loss. The marginal cost and benefit schedules from the Appendix are structured such that the marginal cost of abatement is the steeper of the two 
curves. This in mind, the deadweight loss from this third regulatory round will likely be the smallest of the three rounds.

\section{DISCUSSION}

This game can generate a rich class discussion. To begin, the instructor may use the game to highlight the predictions and assumptions of economic theory. For instance, experience suggests that both market-oriented frameworks will outperform the uniform command-andcontrol standard. Students should be able to see that this is due the market-oriented frameworks' flexibility in dealing with heterogeneous abatement costs. More formally, Table 1 details the marginal benefit and aggregated marginal cost schedules from the Appendix. The marginal benefit and marginal cost of abatement are equated when industry reduces pollution by 18 tons with low-cost Ace reducing its pollution by 12 tons while high-cost Deuce reduces its by just six tons. Using the total benefit and total cost figures from the Appendix, this level of abatement brings about $\$ 1,017$ in total benefits at a total cost to industry of just $\$ 480$ - a substantially greater net benefit than if both firms were forced to reduce pollution by a uniform nine tons.

\section{[Insert Table 1 about here]}

Students may also discover that market-oriented frameworks can lead to a "costeffective" solution even if the government chooses an inefficient tax level or number of permits. For example, facing a tax rate of \$24 per ton (half of the efficient level), low-cost Ace should still reduce its pollution by twice as much as high-cost Deuce. The same should hold if the government auctions off 24 permits instead of the optimal 12 . This is especially pertinent given that pollution targets are, in practice, influenced as much by political expediency as by economic efficiency (Joskow and Schmalensee 1998). 
This game can also highlights the difference between market-oriented abatement frameworks. For example, astute students will realize that tax and permit schemes present different incentives for firms to strategically misrepresent abatement costs. Firms have an incentive to understate their marginal abatement costs in anticipation of an emissions tax because this could lead to the actual tax rate being set below the optimal level. Conversely, firms have an incentive to overstate their marginal abatement costs in anticipation of a permit framework because this could lead the regulator to issue permits in excess of the optimal number. Occasionally students have recognized this at the outset of the game and have "split the difference" by honestly answering the regulator's questions in the game's first phase.

The game's results generally show that while both market-oriented regulatory frameworks outperform command-and-control regulation, taxes outperform permits given the built in uncertainty and the relative slopes of the marginal benefit and cost curves. For example, if the regulator were to overestimate marginal abatement cost by a factor of two, Table 1 suggests they would require each firm to reduce pollution by five tons under the command-and-control framework, they would issue 20 permits under the cap-and-trade framework, and they would set a $\$ 56$ per-ton emissions tax. Command-and-control would yield 10 tons of abatement and $\$ 425$ in net benefits (a $\$ 112$ deadweight loss relative to the efficient outcome). Tradable permits would yield 10 tons of abatement and $\$ 445$ in net benefits (a $\$ 92$ deadweight loss relative to the efficient outcome). And a tax would yield 21 tons of abatement and $\$ 511$ in net benefits (just a $\$ 26$ deadweight loss relative to the efficient outcome).

While this result can be shown graphically, the intuition can be challenging for students to grasp. A few minutes of discussion should help students see that when marginal abatement costs are initially low but then increase quickly, placing an inflexible cap on emissions through 
permits can lead to situations where the marginal cost of the last ton of abatement is dramatically greater than or less than the marginal benefit from that last ton. Placing an upper limit on marginal abatement cost using a tax, on the other hand, allows firms to pollute more or less than regulators originally envisioned, which in this scenario can lead to a more efficient outcome.

The instructor should stress, however, that taxes will not always outperform permits. The regulatory framework likely to yield the more efficient outcome depends critically on the nature of the pollutant and the associated abatement technology. McKibbin and Wilcoxen (2002) argue that because of the long-lived nature of $\mathrm{CO}_{2}$ in the atmosphere, the marginal damage from $\mathrm{CO}_{2}$ emissions in any given year (or, alternatively, the marginal benefit from $\mathrm{CO}_{2}$ abatement) is roughly constant. The marginal cost of abatement in any given year, on the other hand, increases rapidly as firms and households quickly exhaust low-cost abatement alternatives (e.g., switching to compact-florescent light bulbs) and have to turn to more expensive technologies (e.g., replacing electricity from coal-fired power plants with more expensive renewable energy). Under these assumptions a tax will generally outperform permits from an efficiency standpoint.

In other cases permits will outperform a tax. In the case of sulfur dioxide $\left(\mathrm{SO}_{2}\right)$ emissions linked to respiratory illness and acid rain, for example, the marginal damage from emissions in any given time period increase rapidly as ground-level $\mathrm{SO}_{2}$ concentrations cross the threshold for human safety (Chestnut and Mills 2005). The marginal cost of abatement, in contrast, is relatively flat given that the primary means for reducing $\mathrm{SO}_{2}$ is switching to low-sulfur coal from Utah's Powder River Basin (Schmalensee et al. 1998).

The instructor may also ask students to think about the extent to which the ordering of rounds influenced outcomes. For example, did command-and-control underperform the marketoriented approaches simply because it was the first regulatory regime firms encountered? What, 
if anything, did firms learn in the command-and-control and permit rounds that they could have used to gain a strategic advantage in the final tax round?

Finally, the instructor may wish to spend a few minutes on the nature of uncertainty in this exercise and in environmental policy more generally. Here, polluters had perfect information about their abatement costs, but the regulator received only an imperfect signal of those costs. In reality it is more likely that no party will have perfect information. For example, in the case of $\mathrm{CO}_{2}$ emissions it is impossible to predict with any certainty what abatement technologies will be available in ten years, let alone how much those technologies will cost to implement. Season-toseason temperature fluctuations will influence the demand for heating fuels, effecting the cost of achieving any given emissions target. The benefits of $\mathrm{CO}_{2}$ abatement are also necessarily uncertain given the vagaries of forecasting the climate decades into the future. This is not necessarily an argument against regulation, but policy makers should be aware of the ways different regulatory frameworks perform in the presence of uncertainty.

Instructors have a wealth of additional readings to chose from regarding market-oriented pollution control frameworks, especially as they relate to $\mathrm{SO}_{2}$ and $\mathrm{CO}_{2}$ emissions. Schmalensee et al. (1998) and Stavins (1998) provide brief, accessible overviews of the economics of $\mathrm{SO}_{2}$ allowance trading. McKibbin and Wilcoxen (2002) discuss the strengths and weaknesses of tax and permit frameworks as they relate to $\mathrm{CO}_{2}$ emissions both from the standpoint of economic theory and political economy. Instructors interested in a more popular take on the tax-versuspermit debate might consider Mankiw's (2006) op-ed in the Wall Street Journal and Stavins' (2008) in the Boston Globe. 


\section{NOTES}

' Figures depicting marginal benefit, marginal cost, and deadweight loss under both scenarios are available for download at http://economics.kenyon.edu/corrigan/pollutiongame/.

2For large classes, the instructor may wish to divide students in to two or more "economies" each with its own regulatory agency and industries.

${ }^{3}$ Full versions of the instructions and other useful ancillary materials are available for download at http://economics.kenyon.edu/corrigan/pollutiongame/.

${ }^{4}$ While the instructions are written assuming that the regulator's goal is to maximize society's overall well-being, the instructor may choose to offer the regulator the option of choosing its own objective, taking a moment to point the strengths and/or weaknesses of each approach. For example, the regulator can choose to minimize pollution, but this will impose a high cost on firms and, eventually, their customers. On the other hand, the regulator may choose to maximize permit or tax revenue, though depending on the elasticity of firms' pollution demand this may lead to either too much or too little pollution relative to the socially optimal level.

${ }^{5}$ An instructor wishing to devote more attention to strategic interaction may wish to introduce a Kwerel mechanism. Kwerel (1977) shows that when the regulator (i) issues Z' permits such that the marginal benefit from abatement equals the industry's stated marginal abatement cost, and (ii) commits to buying back unused permits at a price equal to the marginal benefit from abatement at Z', firms can do no better than to accurately report their costs. This would, among other things, serve as a starting point for a discussion of the larger mechanism design literature. However, this approach also adds time and complexity to the exercise. See English and Yates (2007) for a current and accessible review of the recent literature. 


\section{APPENDIX}

The Regulator

In everything you do, your goal is to maximize society's well-being. The problem in front of you right now is the regulation of air pollution generated by industry. While it's virtually impossible for firms to do business without also generating some amount of air pollution, the quantity of pollution can be controlled using any number of techniques (for example, by using inputs more efficiently or by installing abatement equipment). Your crack staff of environmental toxicologists, engineers, and economists has put together the following table describing the benefits society derives from reducing air pollution:

\begin{tabular}{|c|c|c|c|c|c|}
\hline $\begin{array}{c}\text { Tons of Pollution } \\
\text { Abated }\end{array}$ & $\begin{array}{c}\text { Marginal } \\
\text { Benefit }\end{array}$ & $\begin{array}{c}\text { Total } \\
\text { Benefit }\end{array}$ & $\begin{array}{c}\text { Tons of Pollution } \\
\text { Abated }\end{array}$ & $\begin{array}{c}\text { Marginal } \\
\text { Benefit }\end{array}$ & $\begin{array}{c}\text { Total } \\
\text { Benefit }\end{array}$ \\
\hline 1 & $\$ 65$ & $\$ 65$ & 16 & $\$ 50$ & $\$ 920$ \\
\hline 2 & $\$ 64$ & $\$ 129$ & 17 & $\$ 49$ & $\$ 969$ \\
\hline 3 & $\$ 63$ & $\$ 192$ & 18 & $\$ 48$ & $\$ 1,017$ \\
\hline 4 & $\$ 62$ & $\$ 254$ & 19 & $\$ 47$ & $\$ 1,064$ \\
\hline 5 & $\$ 61$ & $\$ 315$ & 20 & $\$ 46$ & $\$ 1,110$ \\
\hline 6 & $\$ 60$ & $\$ 375$ & 21 & $\$ 45$ & $\$ 1,155$ \\
\hline 7 & $\$ 59$ & $\$ 434$ & 22 & $\$ 44$ & $\$ 1,199$ \\
\hline 8 & $\$ 58$ & $\$ 492$ & 23 & $\$ 43$ & $\$ 1,242$ \\
\hline 9 & $\$ 57$ & $\$ 549$ & 24 & $\$ 42$ & $\$ 1,284$ \\
\hline 10 & $\$ 56$ & $\$ 605$ & 25 & $\$ 41$ & $\$ 1,325$ \\
\hline 11 & $\$ 55$ & $\$ 660$ & 26 & $\$ 40$ & $\$ 1,365$ \\
\hline 12 & $\$ 54$ & $\$ 714$ & 27 & $\$ 39$ & $\$ 1,404$ \\
\hline 13 & $\$ 53$ & $\$ 767$ & 28 & $\$ 38$ & $\$ 1,442$ \\
\hline 14 & $\$ 52$ & $\$ 819$ & 29 & $\$ 37$ & $\$ 1,479$ \\
\hline 15 & $\$ 51$ & $\$ 870$ & 30 & $\$ 36$ & $\$ 1,515$ \\
\hline
\end{tabular}

You'll need to find a way to motivate firms to limit air pollution to the efficient level. You'll start by asking firms about their abatement costs (bearing in mind that they may not be entirely truthful in their responses). Once you come up with your best guess of abatement costs, you can determine the optimal level of emissions. With this number in mind, you'll need to determine (1) a uniform abatement standard you'd apply under a command-and-control framework, (2) the number of permits you'd issue under a tradable-emissions-permit framework, and (3) the per-ton tax you'd impose under an emissions-tax framework.

Remember that you're interested in society's well-being, which includes the well-being of polluting firms. So when you're devising your pollution-control strategies, you'd like to find some way to arrive at the efficient level of pollution while imposing the lowest possible costs on industry. 


\section{Ace Energy}

Your goal at Ace is really, really simple: You want to maximize profits. You don't care about trees or flowers or dolphins or anything else. All you want to do is to make the most money you possibly can. On the way to achieving that goal, you want to spend as little as possible on pollution abatement.

Left on your own, you'd generate 15 tons of air pollution every year, though you can reduce that amount by pursuing costly abatement. Your pollution abatement costs are detailed below. The government regulator will ask you questions about these costs and use your answers to design three different pollution control policies. You're free to over- or understate your true costs if you think that's in your best interest.

\begin{tabular}{|c|c|c|}
\hline Tons of Pollution Abated & Marginal Abatement Cost & Total Abatement Cost \\
\hline 1 & $\$ 4$ & $\$ 4$ \\
\hline 2 & $\$ 8$ & $\$ 12$ \\
\hline 3 & $\$ 12$ & $\$ 24$ \\
\hline 4 & $\$ 16$ & $\$ 40$ \\
\hline 5 & $\$ 20$ & $\$ 60$ \\
\hline 6 & $\$ 24$ & $\$ 84$ \\
\hline 7 & $\$ 28$ & $\$ 112$ \\
\hline 8 & $\$ 32$ & $\$ 144$ \\
\hline 10 & $\$ 36$ & $\$ 180$ \\
\hline 11 & $\$ 40$ & $\$ 220$ \\
\hline 12 & $\$ 44$ & $\$ 264$ \\
\hline 13 & $\$ 48$ & $\$ 312$ \\
\hline 14 & $\$ 52$ & $\$ 364$ \\
\hline 15 & $\$ 56$ & $\$ 420$ \\
\hline
\end{tabular}




\section{Deuce Petrochemical}

Your goal at Deuce is really, really simple: You want to maximize profits. You don't care about trees or flowers or dolphins or anything else. All you want to do is to make the most money you possibly can. On the way to achieving that goal, you want to spend as little as possible on pollution abatement.

Left on your own, you'd generate 15 tons of air pollution every year, though you can reduce that amount by pursuing costly abatement. Your pollution abatement costs are detailed below. The government regulator will ask you questions about these costs and use your answers to design three different pollution control policies. You're free to over- or understate your true costs if you think that's in your best interest.

\begin{tabular}{|c|c|c|}
\hline \hline Tons of Pollution Abated & Marginal Abatement Cost & Total Abatement Cost \\
\hline 1 & $\$ 8$ & $\$ 8$ \\
\hline 2 & $\$ 16$ & $\$ 24$ \\
\hline 3 & $\$ 24$ & $\$ 48$ \\
\hline 4 & $\$ 32$ & $\$ 80$ \\
\hline 5 & $\$ 40$ & $\$ 120$ \\
\hline 6 & $\$ 48$ & $\$ 168$ \\
\hline 7 & $\$ 56$ & $\$ 224$ \\
\hline 8 & $\$ 64$ & $\$ 288$ \\
\hline 9 & $\$ 72$ & $\$ 360$ \\
\hline 10 & $\$ 80$ & $\$ 440$ \\
\hline 11 & $\$ 88$ & $\$ 528$ \\
\hline 12 & $\$ 96$ & $\$ 624$ \\
\hline 13 & $\$ 104$ & $\$ 728$ \\
\hline 14 & $\$ 112$ & $\$ 840$ \\
\hline 15 & $\$ 120$ & $\$ 960$ \\
\hline \hline
\end{tabular}




\section{REFERENCES}

Bergstrom, T. C. and J. H. Miller. 1997. Experiments with economic principles. San Francisco: McGraw Hill.

Chestnut, L. G. and D. M. Mills. 2005. A fresh look at the benefits and costs of the US Acid Rain Program. Journal of Environmental Management 77 (3): 252-66

English, D. and A. Yates. 2007. Citizens' demand for permits and Kwerel's incentive compatible mechanism for pollution control. Economics Bulletin 17 (4): 1-9.

Hazlett, D. and L. Bakkensen. 2005. Global trade in $\mathrm{CO}_{2}$ permits: A classroom experiment. Perspectives on Economic Education Research 1 (1): 18-43.

Joskow, P. J. and R. Schmalensee. 1998. The political economy of market-based environmental policy: the U.S. Acid Rain Program. Journal of Law and Economics 41 (1): 89-135.

Kwerel, E. 1977. To tell the truth: Imperfect information and optimal pollution control. Review of Economic Studies 44 (3): 595-601.

Mankiw, N. G. 2006. Raise the gas tax. Wall Street Journal. October 20, 2006.

McKibbin, W. J. and P. J. Wilcoxen. 2002. The role of economics in climate change policy. Journal of Economic Perspectives 16 (2): 107-129.

Schmalensee, R., P. L. Joskow, A. D. Ellerman, J. P. Montero, and E. M. Bailey. 1998. An interim evaluation of sulfur dioxide emissions trading. Journal of Economic Perspectives 12 (3): 53-68.

Stavins, R. N. 1998. What can we learn from the grand policy experiment? Lessons from $\mathrm{SO}_{2}$ allowance trading. Journal of Economic Perspectives 12 (3): 69-88.

Stavins, R. N. 2008. Inspiration for climate change. Boston Globe. November 12, 2008. 
TABLE 1. Marginal Benefit and Marginal Cost Schedules

\begin{tabular}{|c|c|c|c|c|c|c|c|}
\hline Tons of & Marginal & Marginal & Firm Abating & Tons of & Marginal & Marginal & Firm Abating \\
\hline Pollution & Benefit & Cost & & Pollution & Benefit & Cost & \\
\hline Abated & & & & Abated & & & \\
\hline 1 & $\$ 65$ & $\$ 4$ & Ace & 16 & $\$ 50$ & $\$ 44$ & Ace \\
\hline 2 & $\$ 64$ & $\$ 8$ & Ace & 17 & $\$ 49$ & $\$ 48$ & Ace \\
\hline 3 & $\$ 63$ & $\$ 8$ & Deuce & 18 & $\$ 48$ & $\$ 48$ & Deuce \\
\hline 4 & $\$ 62$ & $\$ 12$ & Ace & 19 & $\$ 47$ & $\$ 52$ & Ace \\
\hline 5 & $\$ 61$ & $\$ 16$ & Ace & 20 & $\$ 46$ & $\$ 56$ & Ace \\
\hline 6 & $\$ 60$ & $\$ 16$ & Deuce & 21 & $\$ 45$ & $\$ 56$ & Deuce \\
\hline 7 & $\$ 59$ & $\$ 20$ & Ace & 22 & $\$ 44$ & $\$ 60$ & Ace \\
\hline 8 & $\$ 58$ & $\$ 24$ & Ace & 23 & $\$ 43$ & $\$ 64$ & Deuce \\
\hline 9 & $\$ 57$ & $\$ 24$ & Deuce & 24 & $\$ 42$ & $\$ 72$ & Deuce \\
\hline 10 & $\$ 56$ & $\$ 28$ & Ace & 25 & $\$ 41$ & $\$ 80$ & Deuce \\
\hline 11 & $\$ 55$ & $\$ 32$ & Ace & 26 & $\$ 40$ & $\$ 88$ & Deuce \\
\hline 12 & $\$ 54$ & $\$ 32$ & Deuce & 27 & $\$ 39$ & $\$ 96$ & Deuce \\
\hline 13 & $\$ 53$ & $\$ 36$ & Ace & 28 & $\$ 38$ & $\$ 104$ & Deuce \\
\hline 14 & $\$ 52$ & $\$ 40$ & Ace & 29 & $\$ 37$ & $\$ 112$ & Deuce \\
\hline 15 & $\$ 51$ & $\$ 40$ & Deuce & 30 & $\$ 36$ & $\$ 120$ & Deuce \\
\hline
\end{tabular}

